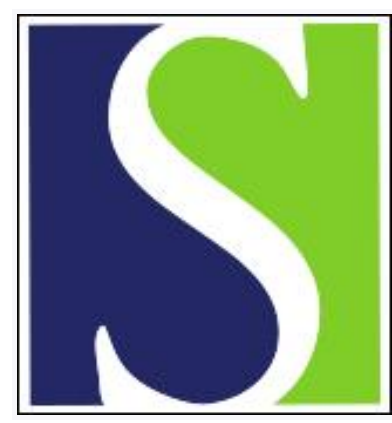

Scand J Work Environ Health 1986;12(5):476-485

https://doi.org/10.5271/sjweh.2115

Issue date: Oct 1986

Systolic blood pressure in relation to occupation and perceived work stress.

by Frommer MS, Edye BV, Mandryk JA, Grammeno GL, Berry G, Ferguson DA

The following article refers to this text: 2014;40(2):109-132

This article in PubMed: www.ncbi.nlm.nih.gov/pubmed/3491422

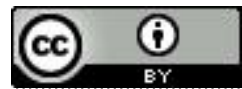




\title{
Systolic blood pressure in relation to occupation and perceived work stress
}

\author{
by Michael S Frommer, MB, BS, MPH, FACOM, ${ }^{1}$ Beryl V Edye, MB, BS, DOH, FACOM, ${ }^{1}$ \\ John A Mandryk, PhD, ${ }^{1}$ Gabrielle L Grammeno, BA(Hons), ${ }^{2}$ Geoffrey Berry, MA, FIS, ${ }^{3}$ \\ David A Ferguson, AM, MD, FRACP, FFOM, FACOM ${ }^{1}$
}

\begin{abstract}
FROMMER MS, EDYE BV, MANDRYK JA, GRAMMENO GL, BERRY G, FERGUSON DA. Systolic blood pressure in relation to occupation and perceived work stress. Scand J Work Environ Health 12 (1986) 476-485. This paper outlines the methods used in a five-year prospective study of 4607 Australian government employees and presents initial cross-sectional results examining associations between systolic blood pressure, occupation, and subjects' perceptions of work stress as ascertained in a questionnaire survey. The questionnaire items were grouped by means of principal component analysis into six factors representing adverse job characteristics. There were appreciable occupational differences in the mean scores for all six factors and in systolic blood pressure. The differences in systolic blood pressure among men from different occupational categories could not be explained by variation in the level of occupational stress perceived and reported by the subjects. Age, occupation, body mass index, and level of perceived stress arising from financial problems were significantly associated with systolic blood pressure level. A multiple linear regression model was used to determine the relationship between systolic blood pressure, age, and occupation after adjustment for the effects of the other variables.
\end{abstract}

Key terms: coronary heart disease risk, financial problems, hypertension, principal component analysis.

Despite declining mortality, coronary heart disease (CHD) remains the leading cause of death in Australia $(4,14)$. It is also the leading cause of premature retirement attributed to organic disease and of death prior to retirement (7). Although CHD is not regarded as an occupational disease, it has been suggested that aspects of work could contribute to the risk $(1,11,16$, $17,21,29)$. This possibility is strengthened by occupational variations in the occurrence of CHD and in distributions of CHD risk factors, including blood pressure $(10,16,21)$. The question therefore arises of whether the differences in CHD risk are due to occupational influences or to constitutional and environmental factors distributed differentially among occupations.

Union concerns about the possible link between work stress and CHD led to the planning of a blood pressure study within the School of Public Health and Tropical Medicine in Sydney. While there is no generally accepted measure of harmful stress, the risk of CHD has been found to vary with occupational level (16), responsibility at work (29), job control in relation to work load (1), support for the worker from

1 National Occupational Health and Safety Commission and The University of Sydney, Sydney, Australia.

2 Sydney Hospital Occupational Health and Safety Service, Sydney, Australia.

${ }^{3}$ School of Public Health and Tropical Medicine and The University of Sydney, Sydney, Australia.

Reprints requests to: Dr MS Frommer, National Occupational Health and Safety Commission, Box 58 GPO, Sydney NSW 2001, Australia. supervisors, colleagues and family (17), and type A or type B behavior pattern (26). This study has taken the approach of ranking subjects' reactions to perceived work stress.

Occupational differences in CHD are important industrially and have implications for the prevention of CHD. Worksite intervention could be effective in reducing CHD risk $(8,27)$. The efficiency of intervention may depend on the distribution of risk in working populations.

Accordingly, the blood pressure study was planned with the following three major objectives: (i) to identify occupational factors associated with CHD risk, (ii) to observe the progression and community control of hypertension and other CHD risk indicators in different occupational groups, and in relation to occupational change, and (iii) to conduct a trial of riskfactor modification based on counseling by occupational nurses.

This paper outlines the structure of and methods used in the blood pressure study. It then presents results on the association of occupation and blood pressure among the men and on the contribution of subjects' reactions to perceived work stress to this association.

\section{Subjects and method}

The first objective was addressed by a cross-sectional survey which provided the base line for the prospective research appropriate to the second and third objectives. The second objective was addressed by a 
cohort study, and the third by a randomized controlled trial of intervention.

The study population consisted of 4607 Australian government employees working in Sydney. They were recruited on a voluntary basis between April 1977 and October 1980. Seventy-five percent of the subjects were recruited from Telecom Australia, $24 \%$ from the Australian Taxation Office, and $1 \%$ from Australia Post. Table 1 gives a breakdown of the study population by employer and sex.

The initial data collection from each subject took place in worktime during two visits to the study center, located in Telecom premises in Sydney. On the first visit subjects underwent preliminary screening by a nurse and answered a self-administered work response questionnaire developed to record reactions to perceived work stress. This questionnaire also included items on personal relationships and domestic and financial problems, as well as items designed to identify the type A behavior pattern. The preliminary screening comprised interviewer-administered questions seeking demographic and occupational information, measurement of pulse rate and blood pressure, a 12-lead electrocardiogram, anthropometry, collection of a random venous blood sample for hematology and biochemical analysis, and collection of a midstream urine specimen for microscopy.

The subjects returned about two weeks later for medical assessment. In the interim they completed a biographical questionnaire which included items on personal health, medications, family history of cardiovascular disease, tobacco and alcohol consumption, diet, leisure-time activities, and additional occupational and demographic details. Medical assessment consisted of a physical examination focusing on the cardiovascular system and a simple test of heart rate response to physical exertion. Measurements of pulse rate and blood pressure were repeated under conditions identical to those of the preliminary screening and followed the methods proposed by the World Health Organization for cardiovascular surveys (22). Hawksley random-zero sphygmomanometers were used for blood pressure determination, the reading being made after the subject had been seated at rest for $15 \mathrm{~min}$.

The physician conducting the medical assessment evaluated the screening data, relevant biographical data and laboratory results, discussed these results and the physical findings with the subject, and then assigned the subject to one of four CHD risk categories depending on diastolic blood pressure, serum cholesterol level, mean skinfold thickness from three sites, heart rate response to exertion, cigarette smoking, and alcohol consumption. The presence of significant electrocardiographic abnormalities and the use of hormonal contraception by women over the age of 40 years were also taken into account. The criteria for risk categorization are summarized in table 2.

Subjects under treatment for cardiovascular and related disorders at enrollment were placed in a separate group for observation, irrespective of the assigned risk level. Subjects with risk levels II and III entered the intervention trial and were randomized into intervention and reference groups. Intervention consisted

Table 1. Blood pressure study population by employer and sex.

\begin{tabular}{lcccc}
\hline Sex & $\begin{array}{c}\text { Telecom } \\
\text { Australia }\end{array}$ & $\begin{array}{c}\text { Australian } \\
\text { Taxation } \\
\text { Office }\end{array}$ & $\begin{array}{c}\text { Australia } \\
\text { Post and } \\
\text { other }\end{array}$ & Total \\
\hline Male & 2515 & 791 & 39 & 3345 \\
Female & 875 & 379 & 8 & 1262 \\
\hline
\end{tabular}

Table 2. Criteria for risk categorization.

\begin{tabular}{|c|c|c|c|c|}
\hline \multirow{2}{*}{ Criterion } & \multicolumn{4}{|c|}{ Risk level } \\
\hline & 1 & 11 & III & IV \\
\hline $\begin{array}{l}\text { Diastolic blood } \\
\text { pressure in } \mathrm{mm} \mathrm{Hg} \text { a }\end{array}$ & $<85(<11332)$ & $85-94(11332-12664)$ & $95-104(12665-13865)$ & $>104(>13865)$ \\
\hline $\begin{array}{l}\text { Serum cholesterol } \\
(\mathrm{mmol} / \mathrm{l})\end{array}$ & $<6.4$ & $6.4-7.0$ & $7.1-7.7$ & $>7.7$ \\
\hline Cigarettes (number/d) & $0-4$ & $5-20$ & $21-40$ & $>40$ \\
\hline Alcohol (drinks b/week) & $0-30$ & $31-50$ & $51-70$ & $>70$ \\
\hline $\begin{array}{l}\text { Mean skinfold } \\
\text { thickness }{ }^{c}(\mathrm{~mm})\end{array}$ & $<15$ & $15-19$ & $20-24$ & $>24$ \\
\hline $\begin{array}{l}\text { Heart rate response } \\
\text { to exercise }{ }^{d}\end{array}$ & $A, B$ & C & $D$ & $E$ \\
\hline
\end{tabular}

a Pascal equivalent in parentheses.

b One drink equivalent to $10 \mathrm{~g}$ of alcohol.

c Mean from three sites: subscapular, iliac crest, and triceps folds.

$\checkmark$ Heart rate (HR) response to physical exercise: the subject was required to step up with both feet onto a box $20 \mathrm{~cm}$ high at a rate of 30 steps per minute. HR was measured after each complete minute of stepping. Results were recorded as follows: A: $H R \leq 120 / \mathrm{min}$ after $3 \mathrm{~min}$ of stepping, B: HR $\leq 120 / \mathrm{min}$ after $2 \mathrm{~min}$ of stepping but $>120$ after $3 \mathrm{~min}, \mathrm{C}: \mathrm{HR} \leq 120 / \mathrm{min}$ after $1 \mathrm{~min}$ of stepping but $>120$ after $2 \mathrm{~min}, \mathrm{D}: H R \geq 120 / \mathrm{min}$ after $1 \mathrm{~min}$ of stepping, and $\mathrm{E}$ : resting $\mathrm{HR}>100 / \mathrm{min}$ or resting $H R \leq 100 / \mathrm{min}$ but increasing by $10 / \mathrm{min}$ or more on standing. The test was omitted if the subject was taking beta-adrenergic blocking drugs for any reason or had any contraindicating physical condition. It was abandoned when HR exceeded 120/min or if result $\mathrm{E}$ was assigned. 
of intensive counseling on risk factor modification by occupational nurses over a three-month period and did not include the prescription of drugs. Subjects with risk level IV not already receiving treatment were referred to their own practitioners or to clinics; many of them required drug therapy. No attempt was made to influence treatment received outside this study, but all subjects were eligible to enter the follow-up program whether or not they were receiving treatment. Clinical data collected on each subject were made available to his or her nominated medical attendant if the subject so wished.

Follow-up routines depended on the assigned risk levels. All subjects were to be followed for five years, regardless of change of employer.

Those with risk levels III and IV, and others receiving treatment on enrollment, were approached annually for review. Those with risk levels I and II were scheduled for review three years after enrollment, and again two years later. At each review the procedure was the same as initially, screening being followed by separate medical assessment.

Apart from the intensive counseling during the three months after enrollment, the intervention and reference groups participated in the same follow-up routines as the subjects not in the intervention trial. Thus the intervention trial of selected subjects was nested within the cohort study of all the subjects, and conducted concurrently with it.

Any subject found to have elevated CHD risk or any other significant abnormality during any follow-up assessment was appropriately counseled or referred by the study physician, irrespective of base-line risk level or status in the intervention trial. Thus all subjects were eligible to receive some intervention in the study. The desigrated intervention and reference groups were distinguished by their risk factor levels on enrollment and by their random allocation to the intervention or reference group. This arrangement satisfied the ethical requirement to inform subjects of any clinical abnormalities detected during follow-up. Moreover, it simulated the operation of an occupational health service which provided counseling for employees within the context of numerous community sources of health advice.

The work response questionnaire was developed specifically for the blood pressure study, as no established instrument could be found to estimate response to physical and mental work stressors satisfactorily. The questions addressed recent perceived mental stress, with items on personal relationships, money and health (4 questions); job or people at work (1 question); frequency (14 questions) and amount (16 questions) of feelings about work; support ( 3 questions); physical symptoms experienced in reaction to work (12 questions); and behavior pattern (15 questions). The items were selected from many literature sources $(2,5,12$, $18,19)$ and from earlier studies $(6)$ as being potential indicators of work distress. Subjects were asked to rank their -esponses to each item on a five-point scale in which the lowest rank represented no distress and the highest rank a high level of distress.

The present analysis deals with the 30 items on feelings about work, the three items on support, and one item on recent perceived mental stress referring to the job or people at work. These 34 questions, which are listed in appendix 1 , were grouped by means of principal component analysis using the Statistical Package for the Social Sciences (20). Six factors, together accounting for $50.2 \%$ of the total variance, were identified. These factors accorded with prior logical grouping of the information sought in the questionnaire.

Details of the principal component analysis are given in appendix 2. Factor I represents boredom. It places weight on the subject's degree of interest in, involvement in, and satisfaction derived from work. Factor II represents lack of support. It places weight on the quality of communication surrounding the subject in the workplace, ie, support from supervisors and colleagues, consultation by management and supervisors, understanding of job responsibilities, and availability of counseling. Factor III represents quantitative overload, ie, time pressure, work load, and the imposition of conflicting demands. Factor IV represents qualitative overload, for example, level of responsibility, complexity of work, and contact with the public. Factor $\mathrm{V}$ represents inadequacy of remuneration and prospects, ie, perceived adequacy of salary in relation to the nature of the job, present and future appreciation of skills by the employer, present and future relevance of skills, and opportunities for advancement. Factor VI represents unsatisfactory physical work conditions, including noise, ventilation, and workspace.

Based on the principal component analysis, a total score for each of the six factors was computed for each subject as outlined in appendix 2 . A high score on any factor represented perception of, and a strong reaction to, the adverse job characteristics identified in the factor.

Because of the need to disentangle any possible effect of nonwork distress, responses to the following three questions from the questionnaire were also examined: (i) how much, if any, stress or worry have you had lately with your spouse or other person you are intimatcly involved with, (ii) how much, if any, stress or worry have you had lately with other members of your family or close friends, and (iii) how much, if any, stress or worry have you had lately with money or home finance. (These items were not included in the principal component analysis.)

\section{Results}

The results described have been confined to men employed by Telecom and the Taxation Office. Data collection was complete for $3246(98.2 \%)$ of the 3306 men, who were divided into the following eight occu- 
pational categories (table 3): (i) executives and administrators, (ii) professionals, (iii) technicians, (iv) clerks, (v) tax investigators and valuers, (vi) tax assessors, (vii) skilled tradesmen, and (viii) other blue-collar workers. One hundred and eighty-six men were receiving drug treatment for hypertension (5.7\%); in 115 of these, systolic blood pressure was less than $160 \mathrm{~mm} \mathrm{Hg}$ (21 $331 \mathrm{~Pa}$ ) and diastolic pressure less than $95 \mathrm{~mm} \mathrm{Hg}$ (12 $665 \mathrm{~Pa})$.

The association between scores for the questionnaire factors, age, and occupational category was examined. Table 4 gives the mean score for each factor by age. An analysis of variance demonstrated that score was significantly related to age for factors I, II, III, V and VI $(p<0.001)$ and to occupation for all six factors $(p<0.001)$. There was no interaction effect between age and occupation. Table 5 gives the mean factor scores for the occupational categories, adjusted for age with the use of partial regression coefficients.

Thus concerns related to factor I (boredom) were prominent in the tax assessor category; to factor II (lack of support) in the clerical category; to factor III (quantitative overload) in the administrative and professional categories; to factor IV (qualitative overload) in the tax investigator, technical, skilled trades and other blue-collar categories; to factor V (inadequacy of remuneration and prospects) in the technical, skilled trades, and other blue-collar categories; and to factor VI (unsatisfactory physical work conditions) in the skilled trades category.
The next step was to explore associations between occupation and systolic blood pressure and to determine whether work stress reported in the questionnaire was related to occupational variations in systolic blood pressure. The following extraneous variables were considered likely to complicate relationships between the occupational variables, including work stress, and systolic blood pressure:

Age.

Table 3. Age distributions for the subjects in different occupational categories.

\begin{tabular}{lcccc}
\hline \multirow{2}{*}{$\begin{array}{l}\text { Occupational } \\
\text { category }\end{array}$} & \multicolumn{5}{c}{ Age group (years) } \\
\cline { 2 - 5 } & $\begin{array}{c}<5 \\
(\%)\end{array}$ & $\begin{array}{c}35-44 \\
(\%)\end{array}$ & $\begin{array}{c}45-54 \\
(\%)\end{array}$ & $\begin{array}{r}>54 \\
(\%)\end{array}$ \\
\hline $\begin{array}{l}\text { Administrators }(\mathrm{N}=338) \\
\text { Professionals }(\mathrm{N}=195)\end{array}$ & 36 & 16 & 25 & 23 \\
Technicians $(\mathrm{N}=1002)$ & 53 & 22 & 20 & 14 \\
Clerks $(\mathrm{N}=910)$ & 67 & 11 & 12 & 11 \\
$\begin{array}{l}\text { Tax investigators and } \\
\text { valuers }(\mathrm{N}=195)\end{array}$ & 40 & 17 & 25 & 18 \\
$\begin{array}{l}\text { Tax assessors }(\mathrm{N}=206) \\
\text { Skilled tradesmen }\end{array}$ & 45 & 8 & 24 & 23 \\
$\begin{array}{l}\mathrm{N}=271) \\
\text { Other blue-collar }\end{array}$ & 43 & 20 & 21 & 16 \\
workers (N =129) & 54 & 16 & 13 & 17 \\
\hline $\begin{array}{l}\text { All occupations } \\
\text { (N=3 246) }\end{array}$ & 53 & 17 & 17 & 14 \\
\hline
\end{tabular}

Table 4. Mean factor scores, determined in the principal component analysis, by age group.

\begin{tabular}{lcccrrr}
\hline \multirow{2}{*}{ Age group } & \multicolumn{5}{c}{ Mean factor score } \\
\cline { 2 - 7 } & Factor I & Factor II & Factor III & Factor IV & Factor V & Factor VI \\
\hline$<35$ & 0.16 & 0.05 & 0.02 & 0.03 & 0.17 & -0.01 \\
$35-44$ & -0.12 & -0.04 & 0.16 & 0.12 & 0.12 & -0.05 \\
$45-54$ & -0.32 & -0.01 & 0.22 & 0.12 & -0.02 & -0.18 \\
$>54$ & -0.40 & -0.25 & 0.15 & 0.05 & -0.16 & -0.22 \\
\hline All ages $^{2}$ & -0.04 & -0.01 & 0.09 & 0.06 & 0.08 & -0.08 \\
\hline
\end{tabular}

a Mean scores for all ages differ from 0 because the factors were deternined from the entire study population, whereas these results refer to a subpopulation of men.

Table 5. Mean factor scores, determined in the principal component analysis, by occupational categories, adjusted for age.

\begin{tabular}{|c|c|c|c|c|c|c|}
\hline \multirow{2}{*}{$\begin{array}{l}\text { Occupational } \\
\text { category }\end{array}$} & \multicolumn{6}{|c|}{ Mean factor score } \\
\hline & Factor 1 & Factor II & Factor III & Factor IV & Factor $\mathrm{V}$ & Factor $\mathrm{V}$ \\
\hline Administrators & -0.33 & 0.02 & 0.68 & -0.03 & -0.40 & -0.22 \\
\hline Professionals & -0.25 & 0.03 & 0.61 & -0.05 & 0.03 & -0.32 \\
\hline Technicians & -0.14 & 0.01 & 0.05 & 0.17 & 0.30 & -0.09 \\
\hline Clerks & 0.20 & 0.05 & 0.04 & -0.06 & 0.14 & -0.02 \\
\hline \multicolumn{7}{|l|}{ Tax investigators } \\
\hline and valuers & -0.02 & -0.04 & 0.20 & 0.18 & -0.37 & -0.19 \\
\hline Tax assessors & 0.57 & -0.17 & -0.04 & -0.05 & -0.33 & -0.22 \\
\hline Skilied tradesmen & -0.37 & -0.19 & -0.43 & 0.18 & 0.29 & 0.26 \\
\hline $\begin{array}{l}\text { Other blue-collar } \\
\text { workers }\end{array}$ & -0.28 & -0.04 & -0.39 & 0.16 & 0.29 & 0.07 \\
\hline
\end{tabular}


Body mass index, defined as weight (in kilograms) divided by the square of height (in meters): Body mass index was divided into three categories, after Bray (3), ie, underweight and acceptable weight $(<25)$, overweight $(25-29)$, and obese $(\geq 30)$.

Education: The level of education might have influenced responses to the self-administered questionnaire, which relied heavily on subjects' language comprehension; some parallels between occupational category and level of education are to be expected.

Reported distress unassociated with work: perceived stress in relation to spouse, family members, and close friends and to financial problems.

For each of the six factors, scores were classed into low, medium, and high tertile ranges. Analyses of variance were done comparing the mean systolic pres- sures across the tertile ranges of the six factors, the age groups, the body mass index categories, level of education categories, and tertile ranges of responses to the three nonwork distress items. There was no significant association between the six work stress factors and systolic blood pressure. The only variables to have significant associations with systolic blood pressure were age group $(p<0.001)$, occupational category $(p<0.01)$, body mass index $(p<0.001)$, and perceived stress arising from financial problems $(p<0.001)$. In addition the interaction of age with occupation had a significant effect $(\mathrm{p}<0.01)$.

The mean level of systolic blood pressure was found to increase with age in all occupations, but to the least extent among professionals (table 6), and to increase with increasing body mass index (table 7). However, the mean systolic blood pressure level decreased with increasing levels of perceived stress arising from financial problems (table 8).

Table 6. Mean systolic blood pressure (in $\mathrm{mm} \mathrm{Hg}$ with pascal equivalent in parentheses) by age group and occupational category. ${ }^{\mathrm{a}}$

\begin{tabular}{|c|c|c|c|c|c|}
\hline \multirow{2}{*}{$\begin{array}{l}\text { Occupational } \\
\text { category }\end{array}$} & \multicolumn{4}{|c|}{ Age group (years) } & \multirow{2}{*}{ All ages } \\
\hline & $<35$ & $35-44$ & $45-54$ & $>54$ & \\
\hline Administrators & $125.4(16718)$ & $126.6(16878)$ & $136.2(18158)$ & $136.9(18252)$ & $130.9(17452)$ \\
\hline Professionals & $120.6(16078)$ & 125.4 (16 718) & $129.0(17198)$ & $126.1(16812)$ & $124.1(16545)$ \\
\hline Technicians & $124.3(16572)$ & 127.2 (16 958) & $127.9(17052)$ & $134.8(17972)$ & $126.4(16852)$ \\
\hline Clerks & $123.2(16425)$ & $125.8(16772)$ & $135.0(17998)$ & $136.6(18212)$ & $126.3(16838)$ \\
\hline $\begin{array}{l}\text { Tax investigators } \\
\text { and valuers }\end{array}$ & $125.4(16718)$ & 125.2 (16 692) & $134.4(17918)$ & $139.4(18585)$ & $130.2(17358)$ \\
\hline Tax assessors & $124.1(16545)$ & 129.7 (17 292) & $135.1(18012)$ & 137.2 (18 292) & $130.1(17345)$ \\
\hline Skilled tradesmen & $125.1(16678)$ & $124.1(16545)$ & $130.3(17372)$ & $139.6(18612)$ & $126.8(16905)$ \\
\hline Other blue collar & $122.7(16358)$ & $124.1(16545)$ & $131.1(17478)$ & 140.5 (18 732) & $127.0(16932)$ \\
\hline All occupations & $123.6(16478)$ & $126.3(16838)$ & $132.1(17612)$ & $136.4(18185)$ & $127.2(16958)$ \\
\hline
\end{tabular}

a Standard deviation (pooled estimate) $=13.9 \mathrm{~mm} \mathrm{Hg}(1853 \mathrm{~Pa})$.

Table 7. Mean systolic blood pressure (in $\mathrm{mm} \mathrm{Hg}$ with pascal equivalent in parentheses) by age group and body mass index. ${ }^{\mathrm{a}}$

\begin{tabular}{|c|c|c|c|c|c|}
\hline \multirow{2}{*}{$\begin{array}{l}\text { Body mass } \\
\text { index }\end{array}$} & \multicolumn{4}{|c|}{ Age group (years) } & \multirow{2}{*}{ All ages } \\
\hline & $<35$ & $35-44$ & $45-54$ & $>54$ & \\
\hline $\begin{array}{l}<25 \\
25-29 \\
\geq 30\end{array}$ & $\begin{array}{l}121.6(16212) \\
126.7(16892) \\
131.7(17558)\end{array}$ & 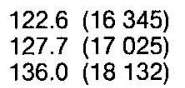 & $\begin{array}{l}129.5(17265) \\
133.7(17825) \\
135.4(18052)\end{array}$ & $\begin{array}{l}132.8(17705) \\
137.9(18385) \\
142.8(19038)\end{array}$ & $\begin{array}{l}123.8(16505) \\
130.5(17398) \\
135.5(18065)\end{array}$ \\
\hline
\end{tabular}

a Standard deviation (pooled estimate) $=13.7 \mathrm{~mm} \mathrm{Hg}(1826 \mathrm{~Pa})$.

Table 8. Mean systolic blood pressure (in $\mathrm{mm} \mathrm{Hg}$ with pascal equivalent in parentheses) by age group and tertile levels of perceived stress arising from financial problems. ${ }^{a}$

\begin{tabular}{|c|c|c|c|c|c|}
\hline \multirow{2}{*}{$\begin{array}{l}\text { Perceived } \\
\text { stress }\end{array}$} & \multicolumn{4}{|c|}{ Age group (years) } & \multirow{2}{*}{ All ages } \\
\hline & $<35$ & $35-44$ & $45-54$ & $>54$ & \\
\hline $\begin{array}{l}\text { Low } \\
\text { Medium } \\
\text { High }\end{array}$ & $\begin{array}{l}124.1(16545) \\
122.5(16332) \\
122.9(16385)\end{array}$ & $\begin{array}{ll}126.7 & (16892) \\
123.7 & (16492) \\
126.1 & (16812)\end{array}$ & $\begin{array}{l}133.0(17732) \\
129.6(17278) \\
122.1(16278)\end{array}$ & $\begin{array}{l}136.4(18185) \\
137.0(18265) \\
135.9(18118)\end{array}$ & $\begin{array}{l}128.3(17 \text { 105) } \\
124.5(16598) \\
123.8(16505)\end{array}$ \\
\hline
\end{tabular}

a Standard deviation (pooled estimate) $=14.0 \mathrm{~mm} \mathrm{Hg}(1866 \mathrm{~Pa})$. 
On the basis of these results a multiple linear regression model was fitted with systolic blood pressure as the dependent variable. The model contained four main sffects (age group, occupational category, body mass index, and level of perceived stress arising from financial problems), and the interaction effect of age with occupation. The categorical independent variables were recorded as indicator variables. The model explained $16.7 \%$ of the variance.

The mean level of systolic blood pressure within each tertile score range of the six work stress factors was adjusted for age, body mass index, and perceived stress arising from financial problems with the use of the coefficients derived from the regression equation. After adjustment, the mean systolic blood pressure did not vary appreciably across the three score levels of any work stress factor (table 9).

In order to confirm that there was no work stress effect on systolic blood pressure, and no effect of the interaction of work stress and occupation, the model was reconstructed, each of the work stress factors and its interaction with occupational category being added. The resultant change in each case was negligible and nonsignificant.

Finally the mean systolic blood pressure, adjusted for body mass index and the effect of perceived stress arising from financial problems, was calculated for each age group within each occupational category, again with the use of regression coefficients. The results are given in table 10. In the 45- to 54-year age group, the adjusted mean systolic blood pressure ranged from $127 \mathrm{~mm} \mathrm{Hg}(16932 \mathrm{~Pa})$ for technicians to $135 \mathrm{~mm} \mathrm{Hg}(17998 \mathrm{~Pa}$ ) for administrators. In the $>54$-year age group, the range was from $126 \mathrm{~mm} \mathrm{Hg}$ (16 $798 \mathrm{~Pa}$ ) for professionals to $139 \mathrm{~mm} \mathrm{Hg}(18531$ $\mathrm{Pa}$ ) for tax investigators. The variation was not so marked in the younger age groups. Overall, the professional and technical categories had the lowest systolic blood pressures. The increase with age was least in the professional category and greatest in the skilled trades, other blue-collar, and tax investigator categories.

\section{Discussion}

Initial cross-sectional results from the blood pressure study indicate appreciable differences in systolic blood pressure among men of different occupational categories. These differences could not be explained by variation in the level of occupational stress perceived and reported by the men.

These conclusions are presented with two reservations. First, the results pertain to a cross-sectional survey of a volunteer population. While the study was not intended to establish prevalence, the possibility of a volunteer bias cannot be overlooked; relationships between occupational variables and systolic blood pressure could differ between volunteers and nonvolunteers. The base population from which the subjects were drawn cannot be enumerated with any accuracy because major reorganization was taking place within Telecom and the Taxation Office during the recruitment period (1977-1980). Telecom employs about 92000 people throughout Australia, about 30000 of whom are in New South Wales. However, the 3390 male and female Telecom subjects in this study all came from Sydney metropolitan establishments, and the response rate from these establishments was estimated to be about $45 \%$. The response rate from Sydney branches of the Australian Taxation Office was estimated to be about $35 \%$. There are few contemporary data on CHD risk factor distributions in representative samples of employed persons in Australia. It is

Table 9. Mean systolic blood pressure (in $\mathrm{mm} \mathrm{Hg}$ with pascal equivalent in parentheses) by tertile levels of the perceived work stress adjusted for age, body mass index and perceived stress arising from financial problems.

\begin{tabular}{lccc}
\hline \multirow{2}{*}{$\begin{array}{l}\text { Work stress } \\
\text { factor }\end{array}$} & \multicolumn{3}{c}{ Perceived stress (tertile levels) } \\
\cline { 2 - 4 } & Low & Medium & High \\
\hline Factor I & $126.9(16918)$ & $126.8(16905)$ & $128.1(17078)$ \\
Factor II & $127.0(16932)$ & $127.2(16958)$ & $127.3(16972)$ \\
Factor III & $126.9(16918)$ & $127.4(16985)$ & $127.2(16958)$ \\
Factor IV & $127.5(16998)$ & $127.0(16932)$ & $127.1(16945)$ \\
Factor V & $127.7(17025)$ & $127.2(16958)$ & $126.8(16905)$ \\
Factor VI & $127.2(16958)$ & $127.1(16945)$ & $127.3(16972)$ \\
\hline
\end{tabular}

Table 10. Mean systolic blood pressure (in $\mathrm{mm} \mathrm{Hg}$ with pascal equivalent in parentheses) by occupational category and age group, adjusted for body mass index and perceived stress arising from financial problems.

\begin{tabular}{|c|c|c|c|c|}
\hline \multirow{2}{*}{$\begin{array}{l}\text { Occupational } \\
\text { category }\end{array}$} & \multicolumn{4}{|c|}{ Age group (years) } \\
\hline & $<35$ & $35-44$ & $45-54$ & $>54$ \\
\hline Administrators & $125.8(16772)$ & $125.8(13772)$ & $135.0(17998)$ & $135.0(17998)$ \\
\hline Professionals & $122.0(16265)$ & $125.5(16732)$ & $128.8(17$ 172) & $125.9(16785)$ \\
\hline Technicians & $124.8(16638)$ & $126.4(16852)$ & $126.9(16918)$ & $133.4(17785)$ \\
\hline Clerks & $124.4(16585)$ & $125.0(16665)$ & $134.4(17918)$ & $136.0(18132)$ \\
\hline $\begin{array}{l}\text { Tax investigators } \\
\text { and valuers }\end{array}$ & $126.0(16798)$ & $125.9(16785)$ & $133.0(17732)$ & $138.9(18518)$ \\
\hline Tax assessors & $124.6(16612)$ & 129.1 (17 212) & $134.4(17918)$ & $135.8(18105)$ \\
\hline Skilled tradesmen & $122.4(16318)$ & $123.0(16398)$ & $128.8(17172)$ & $137.8(18372)$ \\
\hline $\begin{array}{l}\text { Other blue-collar } \\
\text { workers }\end{array}$ & $123.3(16438)$ & $123.6(16478)$ & 130.5 (17 398) & $138.4(18452)$ \\
\hline
\end{tabular}


therefore difficult to assess whether this large study population is representative.

The second reservation concerns the definition and measurement of occupational stress. Despite much investigation, the concept of stress remains nebulous. The experience of stress ranges from the positive notion of challenge to something much more unpleasant, often surmised to be harmful. Such experience is difficult to define and measure. The measurement of perceived stress in this study follows the precedent of identifying potentially stressful elements of worklife and then asking subjects to rank their reactions (if any) to these elements. The stressful elements are adverse job characteristics about which employed people often complain. They apply in a wide variety of workplaces but cannot be comprehensive for all workplaces.

The self-report process itself introduces difficulties of interpretation. There is evidence that personal variables associated with CHD risk in general, and with elevated blood pressure specifically, can influence reactions to and self-reported perceptions of adverse elements in the work environment (28). For example, elevated resting blood pressure in young men has been found to be associated with high levels of work satisfaction and low levels of aggression (indicated by willingness to reason in conflict situations) (13). Highly motivated people with low levels of verbal aggression may underreport adverse or stressful elements in their work environment. In contrast, people with a known history of hypertension may seek environmental "causes" for their disorder and overreport stressful elements in their work when given the opportunity to do so on a questionnaire. Hypertensives who are aware of their diagnosis may have lower levels of psychological well-being (as measured by selected items from standard psychological test batteries) than normotensives or hypertensives unaware of their diagnosis, and labeled hypertensives may have higher rates of absenteeism than hypertensives who do not know that they have elevated blood pressure (15). The level of psychological well-being may influence responses to questions such as those posed in the work response questionnaire. The relationship between psychological well-being and perceived work stress in hypertensives is not clear. It is also unclear whether absenteeism following labeling as a hypertensive is related to perceptions of stress in the work environment.

The measurement of nonwork distress causes similar difficulties of interpretation. In this study increasing levels of reported stress arising from financial problems were associated with decreasing systolic blood pressure. The reason for this inverse relationship is a matter for speculation. Subjects with higher systolic blood pressure levels were less inclined to report concern over money matters. The possible simple explanation that they were wealthier cannot be tested from the available data.

Since the setting of protocols for this study, other approaches to the evaluation of occupational stress, such as the measurement of physiological markers, have been tried $(9,23,24,25)$. It remains to be seen whether they will offer greater objectivity.

Results from this study on blood pressure reinforce other observations $(11,16,21)$ that there are differences in CHD risk levels among occupational groups. The results suggest that, for systolic blood pressure, a major risk factor, the differences are unlikely to be due to perceived work stress. This conclusion was drawn from cross-sectional data on which it was not possible to examine the influence of such important variables as the length of time in the job. Forthcoming prospective data from the study will provide an opportunity for exploring relationships between occupational change, perceived work stress, and CHD risk.

\section{Acknowledgments}

We wish to thank the participants in the study, and the unions and management of Telecom Australia and the Australian Taxation Office. We also gratefully acknowledge the contributions of Ms O Fijalkowski and other members of the User Services Group, ADP Branch, Commonwealth Department of Health, Canberra; the staff of the School of Public Health and Tropical Medicine; Dr A Long; Dr E Lee; and Dr K Burgess.

\section{References}

1. Alfredsson L, Karasek R, Theorell T. Myocardial infarction risk and psychosocial work environment: An analysis of the male Swedish working force. Soc Sci Med 16 (1982) 463-468.

2. Bortner RW. A short rating scale as a potential measure of pattern A behavior. J Chronic Dis 22 (1969) $87-91$.

3. Bray GA. Definition, measurement and classification of the syndromes of obesity. Int J Obesity 2 (1978) 99-112.

4. Cameron RJ. Causes of death Australia 1981. Australian Bureau of Statistics, Canberra 1983. [Catalogue no 3303].

5. Eysenck HJ. The Eysenck personality inventory. Educational and Industrial Testing Service, San Diego, CA 1968.

6. Ferguson D. An Australian study of telegraphists' cramp. Br J lnd Med 28 (1971) 280-285.

7. Ferguson D. Control of coronary heart disease in the Australian post office. Department of Health, Commonwealth of Australia, Sydney 1973.

8. Foote A, Erfurt JC. Hypertension control at the work site: Comparison of screening and referral alone, referral and follow-up, and on-site treatment. N Engl J Med 308 (1983) 809-813.

9. Frankenhaeuser M. Psychoneuroendocrine approaches to the study of emotion as related to stress and coping. In: Howe HE, Dienstbier RA, ed. Nebraska symposium on motivation 1978. University of Nebraska Press, Lincoln, NE 1979, pp 123-161.

10. Frommer MS, Ferguson DA, Edye BV, Mandryk JA, Berry G, Long AA, Ng TK. The Commonwealth Institute of Health blood pressure study: Occupation and risk 
factors for coronary heart disease. Occup Health Aust NZ 5 (1983) 7-19.

11. Haynes SG, Feinleib M, Kannel WB. The relationship of psychosocial factors to coronary heart disease in the Framingham study: III Eight-year incidence of coronary heart disease. Am J Epidemiol 111 (1980) 37-58.

12. Jenkins CD, Rosenman RH, Zyzanski SJ. The Jenkins activity survey for health prediction. Chapel Hill, NC 1965.

13. Knox SS, Theorell T, Svensson JC, Waller R. The relation of social support and working environment to medical variables associated with elevated blood pressure in young males: A structural model. Soc Sci Med 21 (1985) $525-531$.

14. Leeder SR, Dobson AJ, Gibberd RJ, Lloyd DM. Declining mortality rates from ischaemic heart disease in Australia. Aust NZ J Med 14 (1984) 388-394.

15. McDonald LA, Sackett DL, Haynes RB, Taylor DW. Labelling in hypertension: A review of the behavioral and psychological consequences. J Chronic Dis 37 (1984) 933-942.

16. Marmot MG, Rose G, Shipley M, Hamilton PJS. Empioyment grade and coronary heart disease in British civil servants. J Epidemiol Community Health 32 (1978) 244-249.

17. Medalie JH, Kahn HA, Neufeld HN, Riss E, Goldbourt M. Five-year myocardial infarction incidence: II Association of single variables to age and birthplace. J Chronic Dis 26 (1973) 329-349.

18. Moos R. The family environment scale. Consulting Psychologists Press Inc, Palo Alto, CA 1974.

19. Moos R. The work environment scale. Consulting Psychologists Press Inc, Palo Alto, CA 1974.

20. Nie NH, Hadlai Hull C, Jenkins JG, Steinbrenner K,
Bent DH. Statistical package for the social sciences. McGraw Hill Book C, New York, NY 1975.

21. Opit LJ, Oliver G, Salzberg M. Occupation and blood pressure. Med J Aust 1 (1984) 760-764.

22. Rose GA, Blackburn H. Cardiovascular survey methods. World Health Organization, Geneva 1968.

23. Rose RM, Jenkins CK, Hurst M, Livingston L, Hall RP. Endocrine activity in air traffic controllers at work: I Characterization of cortisol and growth hormone levels during the day. Psychoneuroendocrinology 7 (1982) $101-112$

24. Rose RM, Jenkins CK, Hurst M, Livingston L, Hall RP. Endocrine activity in air traffic controllers at work: II Biological, psychological and work correlates. Psychoneuroendocrinology 7 (1982) 113-124.

25. Rose RM, Jenkins CK, Hurst M, Livingston L, Hall RP. Endocrine activity in air traffic controllers at work: III Relationship to physical and psychiatric morbidity. Psychoneuroendocrinology 7 (1982) 125-134.

26. Rosenman RH, Brand RJ, Jenkins D, Friedman M, Straus R, Wurm M. Coronary heart disease in the Western Collaborative Study: Final follow-up experience after $81 \frac{1}{2}$ years. J Am Med Assoc 233 (1975) 872-877.

27. Ruchlin HS, Melcher LA, Alderman MH. A comparative economic analysis of work-related hypertension care programs. J Occup Med 26 (1984) 45-49.

28. Theorell T, Alfredsson L, Knox S, Perski A, Svensson $\mathrm{J}$, Waller $\mathrm{R}$. On the interplay between socioeconomic factors, personality and work environment in the pathogenesis of cardiovascular disease. Scand J Work Environ Health 10 (1984) 373-380.

29. Theorell T, Floderus-Myrhed B. "Workload" and risk of myocardial infarction - A prospective psychosocial analysis. Int J Epidemiol 6 (1977) 17-21.

\section{Appendix 1}

\section{Items from the work response questionnaire}

The following 34 items from the work response questionnaire were grouped by principal component analysis:

1. How much, if any, stress or worry have you had lately with your job or people at work?

2. How often do you feel under pressure in your work?

3. Is your work less satisfying than you would like?

4. Do you feel insecure about the future of your job?

5. Is your work beyond your understanding or more complex than you can handle?

6. Does your job require you to work faster than you would like?

7. Do you have insufficient time each day to complete your work?

8. Is your work less interesting than you would like?

9. Is your work less varied than you would like?

10. Is there too much variation in work rate for your liking?

11. Is there too little variation in work rate for your liking?
12. Are conflicting demands put on you?

13. Do management, including your immediate supervisor, not consult you as often as you would like on matters that affect you?

14. Are you required in your work to deal with others (including the public) more than you care to?

15. Do you get shown less appreciation than you would care to receive for good work?

16. Do you have more work load than you care to handle?

17. Does your work offer less opportunity than you would like of using skills in which you were trained?

18. Do you feel that your job skills may cease to be of value in a few years?

19. Do you dislike your work?

20. How much do you feel that your opportunities for advancement are not as good as you would like?

21. How boring is your work?

22. Do you have more responsibility than you care to have for the welfare, safety or security of other 
employees?

23. Does your work require more mental concentration than you would like?

24. Do you feel concern about the effects of your work on your health?

25. Do you feel that you are paid much less than you should be in relation to what you do and what others get?

26. Do you feel discouraged from making a complaint to your supervisor?

27. Are you less clear than you would like to be on your job responsibilities?

28. Are you dissatisfied with your physical working conditions (eg, work space, equipment, ventilation, lighting)?

29. Are you bothered by noise at work?

30. Do you feel you cannot get as much counseling at work as you would like on personal problems or ill health?

31. Is work morale poor in your job area?

32. Do you get less support than you would like on work troubles from your supervisor?

33. Do you get less support than you would like on work troubles from other people at work?

34. Do you get less support than you would like on work troubles from your spouse, relatives?

\section{Appendix 2}

\section{Principal component analysis}

Responses to the 34 items from the work response questionnaire listed in appendix 1 were grouped by means of principal component analysis, using a program for principal factoring without iteration from the Statistical Package for the Social Sciences (1). Initially the program generated orthogonal factors in decreasing

Table A. Principal component solution (with varimax rotation) for the work response questionnaire.

\begin{tabular}{|c|c|c|c|c|c|c|c|}
\hline \multirow{2}{*}{ Item number } & \multicolumn{6}{|c|}{ Factor loading } & \multirow{2}{*}{ Communality } \\
\hline & 1 & II & III & IV & V & VI & \\
\hline 1 & 0.12 & 0.41 & 0.56 & 0.14 & -0.01 & -0.07 & 0.51 \\
\hline 2 & -0.02 & 0.26 & 0.73 & 0.15 & -0.02 & -0.00 & 0.62 \\
\hline 3 & 0.78 & 0.21 & 0.12 & 0.01 & 0.14 & -0.01 & 0.69 \\
\hline 4 & 0.21 & 0.29 & 0.08 & 0.17 & 0.35 & -0.11 & 0.30 \\
\hline 5 & 0.05 & 0.16 & 0.11 & 0.58 & -0.15 & -0.19 & 0.43 \\
\hline 6 & 0.01 & 0.00 & 0.74 & 0.18 & 0.05 & 0.10 & 0.59 \\
\hline 7 & -0.06 & -0.01 & 0.72 & 0.06 & 0.02 & 0.11 & 0.54 \\
\hline 8 & 0.87 & 0.11 & -0.02 & -0.01 & 0.13 & 0.05 & 0.78 \\
\hline 9 & 0.82 & 0.10 & -0.06 & -0.01 & 0.13 & 0.09 & 0.71 \\
\hline 10 & 0.05 & 0.08 & 0.31 & 0.36 & 0.19 & 0.00 & 0.27 \\
\hline 11 & 0.65 & 0.06 & -0.05 & -0.02 & 0.09 & 0.06 & 0.44 \\
\hline 12 & 0.02 & 0.36 & 0.61 & 0.06 & 0.14 & -0.03 & 0.52 \\
\hline 13 & 0.14 & 0.59 & 0.23 & -0.09 & 0.28 & 0.02 & 0.51 \\
\hline 14 & 0.00 & 0.11 & 0.10 & 0.52 & 0.07 & 0.15 & 0.33 \\
\hline 15 & 0.20 & 0.47 & 0.19 & 0.02 & 0.39 & 0.13 & 0.46 \\
\hline 16 & -0.02 & 0.06 & 0.71 & 0.25 & 0.08 & 0.09 & 0.59 \\
\hline 17 & 0.47 & 0.12 & 0.03 & 0.02 & 0.48 & -0.00 & 0.47 \\
\hline 18 & 0.29 & 0.13 & -0.05 & 0.20 & 0.47 & -0.03 & 0.37 \\
\hline 19 & 0.76 & 0.17 & 0.12 & 0.13 & 0.01 & -0.01 & 0.63 \\
\hline 20 & 0.33 & 0.23 & 0.04 & -0.09 & 0.62 & 0.05 & 0.56 \\
\hline 21 & 0.83 & 0.13 & -0.07 & 0.03 & 0.05 & 0.11 & 0.73 \\
\hline 22 & -0.09 & 0.04 & 0.12 & 0.60 & 0.18 & 0.08 & 0.43 \\
\hline 23 & 0.03 & 0.06 & 0.25 & 0.67 & 0.02 & 0.10 & 0.53 \\
\hline 24 & 0.19 & 0.18 & 0.35 & 0.33 & 0.07 & 0.19 & 0.34 \\
\hline 25 & -0.08 & 0.10 & 0.16 & 0.13 & 0.67 & 0.24 & 0.56 \\
\hline 26 & 0.13 & 0.64 & 0.04 & 0.10 & 0.18 & 0.04 & 0.47 \\
\hline 27 & 0.09 & 0.51 & 0.10 & 0.32 & 0.07 & -0.12 & 0.40 \\
\hline 28 & 0.17 & 0.21 & 0.08 & 0.03 & 0.11 & 0.72 & 0.61 \\
\hline 29 & 0.05 & 0.17 & 0.13 & 0.11 & 0.03 & 0.73 & 0.59 \\
\hline 30 & 0.16 & 0.46 & 0.04 & 0.22 & 0.10 & 0.32 & 0.40 \\
\hline 31 & 0.37 & 0.44 & 0.18 & -0.01 & 0.17 & 0.23 & 0.45 \\
\hline 32 & 0.15 & 0.73 & 0.12 & -0.02 & 0.13 & 0.12 & 0.60 \\
\hline 33 & 0.05 & 0.57 & 0.16 & 0.11 & 0.03 & 0.17 & 0.40 \\
\hline 34 & 0.07 & 0.40 & 0.02 & 0.16 & -0.03 & 0.11 & 0.20 \\
\hline $\begin{array}{l}\text { Proportion of total } \\
\text { variance }\end{array}$ & $13.5 \%$ & $10.3 \%$ & $10.0 \%$ & $6.3 \%$ & $5.7 \%$ & $4.5 \%$ & $50.2 \%$ \\
\hline
\end{tabular}


order of importance, and then it made a varimax rotation on six factors. The six-factor solution was chosen because it accounted for a satisfactory proportion $(50.2 \%)$ of the total variance while at the same time allowing a coherent interpretation consistent with the intent of the work response questionnaire.

For the purpose of interpretation an item was considered to be represented in any given factor if its factor loading was at least 0.33 . From table $\mathrm{A}$, which gives the factor loadings and communalities, it is evident that the six factors concentrate upon the following items:

Factor I: items 3, 8, 9, 11, 17, 19, 20, 21, 31

Factor II: items 1, 12, 13, 15, 26, 27, 30, 31, 32, 33, 34

Factor III: items $1,2,6,7,12,16,24$
Factor IV: items 5, 10, 14, 22, 23, 24

Factor V: items 4, 15, 17, 18, 20, 25

Factor VI: items 28, 29

The program also generated factor score coefficients for each item in the six factors. In each item the coefficient was multiplied by the corresponding standardized response value of the individual subject. The resulting products were then summed over the 34 items to produce six factor scores for each subject.

\section{References}

1. Nie NH, Hadlai Hull C, Jenkins JG, Steinbrenner K, Bent DH. Statistical package for the social sciences. McGraw Hill Book Co, New York, NY 1975. 